\title{
Note of the Editor on the 20th anniversary of Aquaculture International
}

\author{
Gavin Burnell ${ }^{1}$
}

Published online: 15 April 2016

(C) Springer International Publishing Switzerland 2016

\section{A brief history of the journal}

Aquaculture International was founded in 1993 by the then President Elect of the European Aquaculture Society, Dr. Michael Poxton. It was published by Chapman and Hall as a quarterly journal, and the first issue contained six papers spread over 93 pages. In the early years the contributing authors were mainly from Europe, with the Norwegians being stalwart contributors. In 1999 Kluwer took over Chapman and Hall and became the journal publisher. I have been on the Editorial Board since the first issue and in November 2000 was appointed as the new Editor in Chief following Mike Poxton's resignation.

Another merger occurred in 2008 resulting in Springer as the new publishers. By this time the journal was being published six times a year with approximately 100 pages per issue (6-8 papers). The contributors were still mainly European, but the occasional Asian paper was being published, mainly from China. In the last decade there has been a steady increase in non-European contributions to the extent that there are now, on average, $80 \%$ of papers from countries such as China, India, Malaysia, and Thailand with a steady trickle from emerging aquaculture nations such as Iran and Brazil. This complete change in emphasis from the early days is in fact a much truer reflection of the global aquaculture production where over $75 \%$ of product comes from Asia. In conjunction with the change in nationality of the authorship has come a change in both the range of species covered and the topics researched. Aquaculture International has always embraced new species and new technologies, and nowadays you are just as likely to see a paper on the microsatellite analysis of sea cucumber broodstock as one on the nutrition and growth of sea bass.

Guest editors: Elena Mente and Aad Smaal/European Aquaculture Development since 1993: The benefits of aquaculture to Europe and the perspectives of European aquaculture production.

Gavin Burnell

g.burnell@ucc.ie

1 School of Biological, Earth and Environmental Sciences, University College Cork, Cork, Ireland 
Along with the rapid increase in global aquaculture production has come a huge increase in the number of papers handled by the journal. In 2015 we had 573 manuscripts submitted with an acceptance rate of $20 \%$. The way things are going we could be up to 600 by the end of this year. Our Impact Factor has hovered around 1.00 for the last 5 years, which is OK for the subject area, but leaves plenty of room for improvement. One of the ways we hope to increase our profile is by publishing more review type articles like those contributing to this Special Issue.

The last 20 years has seen aquaculture become a major global production force, and Aquaculture International has played its part in the promotion of excellent science and in the dissemination of both pure and applied knowledge. None of this would be possible without the army of dedicated reviewers who selflessly give of their time and expertise to make sure that only the best manuscripts get published. In particular I must pay tribute to Prof Malcolm Jobling (University of Tromso), who in addition to his regular book reviews, has edited a remarkable 376 papers since the journal adopted the Editorial Manager software in 2001. Aquaculture International is only published online since 2014, and this advance means that not only do we save trees, but also that the time from acceptance to publication is only 11 days.

As we go forward my major concern for the future lies in the changing attitudes to reviewing. When we started the journal there was still a widespread ethos among scientist that it was an honour to be asked to comment on a paper and at the very least it was something you did as a duty if one wanted to get into print oneself. These days I frequently have to send out request to over fifteen people before I get two acceptances. The way in which Editors and publishers tackle this problem will be key to maintaining excellence over the next 20 years. 